\title{
Characterization of casein and alpha lactalbumin of African elephant (Loxodonta africana) milk
}

\author{
M. Madende, ${ }^{*}$ G. Osthoff, ${ }^{* 1}$ H-G. Patterton, ${ }^{*}$ H. E. Patterton, ${ }^{*}$ P. Martin, $†$ and D. J. Opperman ${ }^{*}$ \\ ${ }^{*}$ Department of Microbial, Biochemical and Food Biotechnology, University of the Free State, PO Box 339, Bloemfontein 9300, \\ Republic of South Africa \\ †UMR1313 Génétique Animale et Biologie Integrative, Institut National de la Recherche Agronomique, Domaine de Vilvert - Bâtiment 221, \\ 78350 Jouy-en-Josas, France
}

\begin{abstract}
The current research reports partial characterization of the caseins and $\alpha$-lactalbumin $(\alpha-\mathrm{LA})$ of the African elephant with proposed unique structure-function properties. Extensive research has been carried out to understand the structure of the casein micelles. Crystallographic structure elucidation of caseins and casein micelles is not possible. Consequently, several models have been developed in an effort to describe the casein micelle, specifically of cow milk. Here we report the characterization of African elephant milk caseins. The $\kappa$-caseins and $\beta$-caseins were investigated, and their relative ratio was found to be approximately 1:8.5, whereas $\alpha$-caseins were not detected. The gene sequence of $\beta$-casein in the NCBI database was revisited, and a different sequence in the $\mathrm{N}$-terminal region is proposed. Amino acid sequence alignment and hydropathy plots showed that the $\kappa$-casein of African elephant milk is similar to that of other mammals, whereas the $\beta$-casein is similar to the human protein, and displayed a section of unique AA composition and additional hydrophilic regions compared with bovine caseins. Elephant milk is destabilized by $62 \%$ alcohol, and it is speculated that the $\beta$-casein characteristics may allow maintenance of the colloidal nature of the casein micelle, a role that was previously only associated with $\kappa$-casein. The oligosaccharide content of milk was reported to be low in dairy animals but high in some other species such as humans and elephants. In the milk of the African elephant, lactose and oligosaccharides both occur at high levels. These levels are typically related to the content of $\alpha$-LA in the mammary gland and thus point to a specialized carbohydrate synthesis, where the whey protein $\alpha$-LA plays a role. We report the characterization of African elephant $\alpha$-LA. Homology modeling of the $\alpha$-LA showed that it is structurally similar to crystal structures of other mammalian species, which
\end{abstract}

Received December 5, 2014.

Accepted August 14, 2015.

${ }^{1}$ Corresponding author: osthoffg@ufs.ac.za in turn may be an indication that its functional properties, such as lactose synthesis, should not be impaired. Key words: African elephant, milk, casein, $\alpha$-lactalbumin, protein structure

\section{INTRODUCTION}

Extensive research has been carried out on the milk of economically exploited dairy animals such as cow, goat, sheep, buffalo, and camel. Yet, many properties that are not explicit in the milk of these animals are still not completely understood. Research on milk from nondairy animals, where these properties are explicit, may provide insight.

The first comprehensive study of African elephant (Loxodonta africana) milk was conducted by McCullagh and Widdowson (1970). Later studies by Osthoff and coworkers provided detailed information of protein, fat, and sugar composition (Osthoff et al., 2005, 2007). It was observed that the milk of this species had some unique characteristics.

Milk of most mammalian species contains $\alpha_{\mathrm{S}^{-}}, \alpha_{\mathrm{S}^{-}}$, $\kappa-$, and $\beta-\mathrm{CN}$, which exist as colloidal aggregates of $\mathrm{CN}$ with calcium and phosphate, known as the CN micelle (Walstra, 1999; Farrell et al., 2004). Micelles are responsible for converting milk into a free-flowing, lowviscosity liquid and also provide the means for transportation of high levels of calcium and phosphate in the mammary gland. The CN have AA sequences and structural and functional properties that are different from each other. This is a consequence of different levels of posttranslational modifications such as phosphorylation of Ser (or Thr) and glycosylation of Thr residues, mutational changes in CN genes, proteolysis by indigenous milk proteases, or oxidation of Cys (Swaisgood, 1993; Martin et al., 2003). A great deal of research has gone into unraveling the structure of $\mathrm{CN}$ and the $\mathrm{CN}$ micelles. However, the greatest challenge remains that CN cannot be crystallized for x-ray crystallographic analysis, nor can they be accurately studied by nuclear magnetic resonance spectroscopy (Farrell et al., 2004). Other methods of micelle structure elucidation, such 
as small-angle x-ray scattering and small-angle neutron scattering, have various limitations (Holt et al., 2013). Consequently, several models have been developed in an effort to describe the $\mathrm{CN}$ micelle structure. The most accepted model suggests a cross-linking of CN through hydrophobic regions of the $\mathrm{CN}$ and bridging by calcium phosphate nanoclusters, and that stability is maintained by a localized excess of hydrophobic attraction over electrostatic repulsion (De Kruif, 1999; Horne, 2006).

Although the micelle models best describe micelle structure in bovine milk, it must also be taken into account that the amounts of $\kappa-$ and $\beta-\mathrm{CN}$ vary among species (Horne, 2008). Bovine milk generally has high amounts of $\kappa-\mathrm{CN}$, whereas milk of some nonbovine species, for example horse, human, and rat milk, contains low amounts of $\kappa-\mathrm{CN}$ relative to total $\mathrm{CN}$, approximately $1: 7$ and 1:5 for horse and human $\kappa-\mathrm{CN}$, respectively (Martin et al., 2003). This variability is also evident in human milk, which is one of the most thoroughly studied milks and in which $\alpha_{\mathrm{S}_{2}} \mathrm{CN}$ has not been detected (Martin et al., 2003). Moreover, sheep milk also contains 2 nonallelic forms of $\alpha_{S_{2}}-\mathrm{CN}$ because of an internal deletion of $9 \mathrm{AA}$ residues (Boisnard et al., 1991).

The relative composition of the $\mathrm{CN}$ proteins in the CN micelle also seems to play a role in its stability. Heat and ethanol stability has been studied for milk from several species, and it seems as if the $\alpha_{\mathrm{S1}^{-}}$and $\kappa-\mathrm{CN}$ play the major role. Cow milk contains the highest amounts of these 2 and has the highest stability, compared with other species (Unnikrishnan et al., 1988; Horne and Muir, 1990; Guo et al., 1998; Horne, 2008; Fava et al., 2014).

Results of the current research show that African elephant milk contains high amounts of $\beta-\mathrm{CN}$ and low amounts of $\kappa-\mathrm{CN}$. However, despite the low amounts of $\kappa-\mathrm{CN}$, and like all mammalian milks (Martin et al., 2003), African elephant milk still contains CN micelles. This observation prompted an investigation that focused on the characterization of the $\mathrm{CN}$ of this species.

It was apparent from previous research that lactose and oligosaccharides in African elephant milk both occur at high levels (Osthoff et al., 2005, 2007). This is unusual, because in general, most eutherian species contain lactose as the dominant milk carbohydrate, whereas monotremes, marsupials, and a few other eutherian species contain oligosaccharides as the major carbohydrate (Urashima et al., 2005).

The synthesis of lactose in the mammary tissue is regulated by $\alpha$-LA (Klee and Klee, 1970). However, in the absence of $\alpha$-LA, $\beta$-1,4-galactosyltransferase 1 $(\boldsymbol{\beta}-\mathbf{1}, \mathbf{4}-\mathrm{GT} 1)$ catalyzes the transfer of the galactosyl moiety from UDP-galactose to $\mathrm{N}$-acetylglucosamine to produce $N$-acetyllactosamine, a primary building block of oligosaccharides. Such absence is observed in Cape fur seal milk because of the lack or low level of $\alpha$-LA gene expression (Sharp et al., 2008). Consequently, the levels of lactose and oligosaccharides in milk are directly dependent on the amounts of $\alpha$-LA in the mammary gland (Stacey et al., 1995; Ramakrishnan and Qasba, 2001). Humans possess at least 2 other mammary $\beta$-galactosyltransferases that catalyze the synthesis of $\operatorname{Gal}(\beta 1-3) N$-acetylglucosamine-R and $\operatorname{Gal}(\beta 1-4) N$ acetylglucosamine-R structures (Urashima et al., 2009). The catalytic function of these $\beta$-galactosyltransferases is independent of $\alpha$-LA. Because isoglobotriose $[\mathrm{Gal}(\alpha \mathrm{l}-3) \mathrm{Gal}(\beta 1-4) \mathrm{Glc}]$ is the most abundant of the oligosaccharides in Asian and African elephant milk (Uemura et al., 2006; Osthoff et al., 2008), it is probably the $\beta$-galactosyltransferase that links galactose via an $\alpha$ l-3 bond to the galactosyl moiety of the lactose, that is in competition with $\alpha$-LA in its affinity for lactose, which may result in disproportionate synthesis of oligosaccharides or lactose.

Several crystal structures of $\alpha$-LA from other species have been solved, namely human, goat, baboon, guinea pig, cow, and mouse (Pike et al., 1996). However, these species all produce milk that contains low levels of oligosaccharides and high levels of lactose in their milk (Urashima et al., 2009). Because of the low amounts of African elephant milk available and the difficulty experienced with protein crystallization, we followed the route to identify the presence of $\alpha$-LA in African elephant milk by electrophoresis, determine the sequence by mass spectrometry (MS) and databases, and predict the structure of $\alpha$-LA with homology modeling.

\section{MATERIALS AND METHODS}

\section{Sample Preparation}

Milk samples were collected from 3 African elephants at different stages of lactation. The early-lactation sample was obtained from Bloemfontein Zoological Gardens, South Africa, 4 d after parturition (Osthoff et al., 2005). The other 2 samples were obtained from Welgevonden private game reserve, Vaalwater, South Africa, at 12 and 18 mo of lactation (Osthoff et al., 2007). Protein precipitation was done with acetic acid and trichloroacetic acid according to the method by Igarashi (1995), and the final protein concentration of the samples was determined by the Bradford assay (Bradford, 1976).

\section{Ethanol Stability}

A down-scaled procedure of the ethanol stability test (Fava et al., 2014) was performed by mixing $200 \mu \mathrm{L}$ 
of ethanol (in different concentrations) and $200 \mu \mathrm{L}$ of milk in an Eppendorf tube. After standing for $20 \mathrm{~min}$ at room temperature, the mixtures were centrifuged at $20 \times g$ for 5 min at room temperature. The result of the alcohol stability test was defined as the highest alcohol graduation in which milk did not precipitate as curds. The test was performed on 3 separate fresh samples taken at 3 different days.

\section{Protein Separation and MS}

Following protein precipitation and concentration determination, 2-dimensional (2D) PAGE was carried out according to the method of O'Farrell (1975). The first protein separation (isoelectric focusing) was performed on 7-cm immobilized $\mathrm{pH}$ gradients of 5 to 8 in a PROTEAN IEF cell (Bio-Rad, Johannesburg, South Africa). The following IEF program: $250 \mathrm{~V}$ for $20 \mathrm{~min}$, $4,000 \mathrm{~V}$ for $2 \mathrm{~h}$, and linear gradient to $10,000 \mathrm{~V}$ was applied. The second dimension separation (SDS PAGE) was performed on a $12 \%$ (wt/vol) acrylamide:bis-acrylamide [19:1 (wt/wt)]. Proteins were stained in $0.1 \%$ Coomassie R250 solution. Destaining was performed overnight in a $10 \%$ (vol/vol) acetic acid and $20 \%$ ( $\mathrm{vol} /$ vol) methanol. Individual protein spots on $2 \mathrm{D}$ gels were identified by excising from the gel and subsequently subjected to gelC.MS/MS by using the method described by Piersma et al. (2013). Mass spectrometry analysis was performed on an Orbitrap (XLS, Thermo Scientific, Bremen, Germany) instrument according to the method by Marx et al. (2013). In the latter method, data were acquired using the Xcalibur Software package (Thermo Scientific). The precursor ion scan MS spectra $(\mathrm{m} / z$ 400-2,000) were acquired at a resolution of $\mathrm{R}=$ 60,000 with the number of accumulated ions being 1 $\times 10^{6}$. The 20 most intense ions were identified and fragmented by collision-induced dissociation (CID) in the linear ion trap (number of accumulated ions $1.5 \times$ $10^{4}$ ). The lock mass option (polydimethylcyclosiloxane; $m / z$ 445.120025) enabled accurate mass measurement in the MS mode.

Thermo Proteome Discoverer 1.3 (Thermo Scientific) was used to identify proteins by automated database searching, using the Mascot search engine (Matrix Science, London, UK) of all tandem mass spectra against the Swiss-Prot 57.15, National Center for Biotechnology Information (NCBI) mammalian and Uniprot elephant databases (version 119, March 6, 2013). Carbamidomethyl cysteine was set as fixed modification, and oxidized methionine, $\mathrm{N}$-acetylation, and deamidation (NQ) were selected as variable modifications. The precursor and fragment mass tolerance were set to $10 \mathrm{mg} /$ $\mathrm{kg}$ and $0.8 \mathrm{Da}$, respectively, 2 missed tryptic cleavages were allowed. Proteins were considered as positively identified if at least 2 tryptic peptides per protein could be matched, and at a Mascot significance threshold of $P<0.05$ (Perkins et al., 1999).

\section{Multiple Sequence Alignment and Hydropathy Plots}

The $\beta$-CN AA sequences were retrieved from the NCBI database (http://www.ncbi.nih.gov). The $\beta$-CN sequences of African elephant from the NCBI and Expasy (http://www.expasy.org) databases were suspected to be incorrect and were reviewed. A multiple sequence alignment of $\beta$-CN was done using clustal omega (Sievers et al., 2011). Hydropathy plots (Kyte and Doolittle, 1982) were calculated with a window size of 9 , and a web page program was used to draw the plots (http://gcat.davidson.edu/DGPB/kd/kytedoolittle.htm). The $\alpha$-LA primary AA sequences were retrieved from the NCBI database at http://www. ncbi.nih.gov (African elephant, XP_003405795.1; Guinea-pig, NP_001166360.1; Pig, NP_999525.1; Sheep, NP_001009797.1; Mouse, NP_034809.1; Human, NP_002280.1; Wallaby, AAA31602.1; Possum, AAB97108.1; Yak, ADD71874.1; Ringed seal, ABZ89948.1; Weddell seal, ABS88304.1; Harbor seal, ABZ89950.1; Buffalo, ABG78269.1; Cow, NP_776803.1; Shrew, ELV10891.1; Brahman, ACA00156.1). The multiple sequence alignment of the retrieved $\alpha$-LA sequences was performed using the program Clustal omega 1.2.0 with default settings (http://www.ebi. ac.uk/Tools/msa/clustalo/).

\section{Homology Modeling}

All computations were performed on a Gigabyte Intel Core i7 workstation running Ubuntu 12.04 Linux. The protein sequence of African elephant $\alpha$-LA from the Orbitrap MS analysis and the genomic sequence of $\beta-1,4-G T 1$ were subjected to homology modeling. By using the program YASARA, the 3-dimensional models of African elephant $\alpha$-LA and $\beta-1,4-G T 1$ were automatically constructed (Krieger et al., 2002).

\section{RESULTS AND DISCUSSION}

The proteins of African elephant milk were resolved by 2D PAGE (Figure 1), and the numbered protein spots were identified by Orbitrap MS (Table 1). All proteins were first identified by comparison with proteins of other species, of which the number of comparisons and the species of highest identity are shown in Table 1, as well as the Uniprot African elephant gene database. The $\beta$-CN seemed to be the major protein in the milk of the African elephant. Spots 5 to 8 (Figure 1) were 
Table 1. Protein spot identification of African elephant milk proteins from the 2-dimensional PAGE gel of Figure 1 by Orbitrap MS (Thermo Scientific, Bremen, Germany) analysis and the Swiss-Prot database, for homology with proteins of other species as well as the Uniprot elephant database (http://www.uniprot.org/; http://web.expasy.org/docs/swiss-prot_guideline.html)

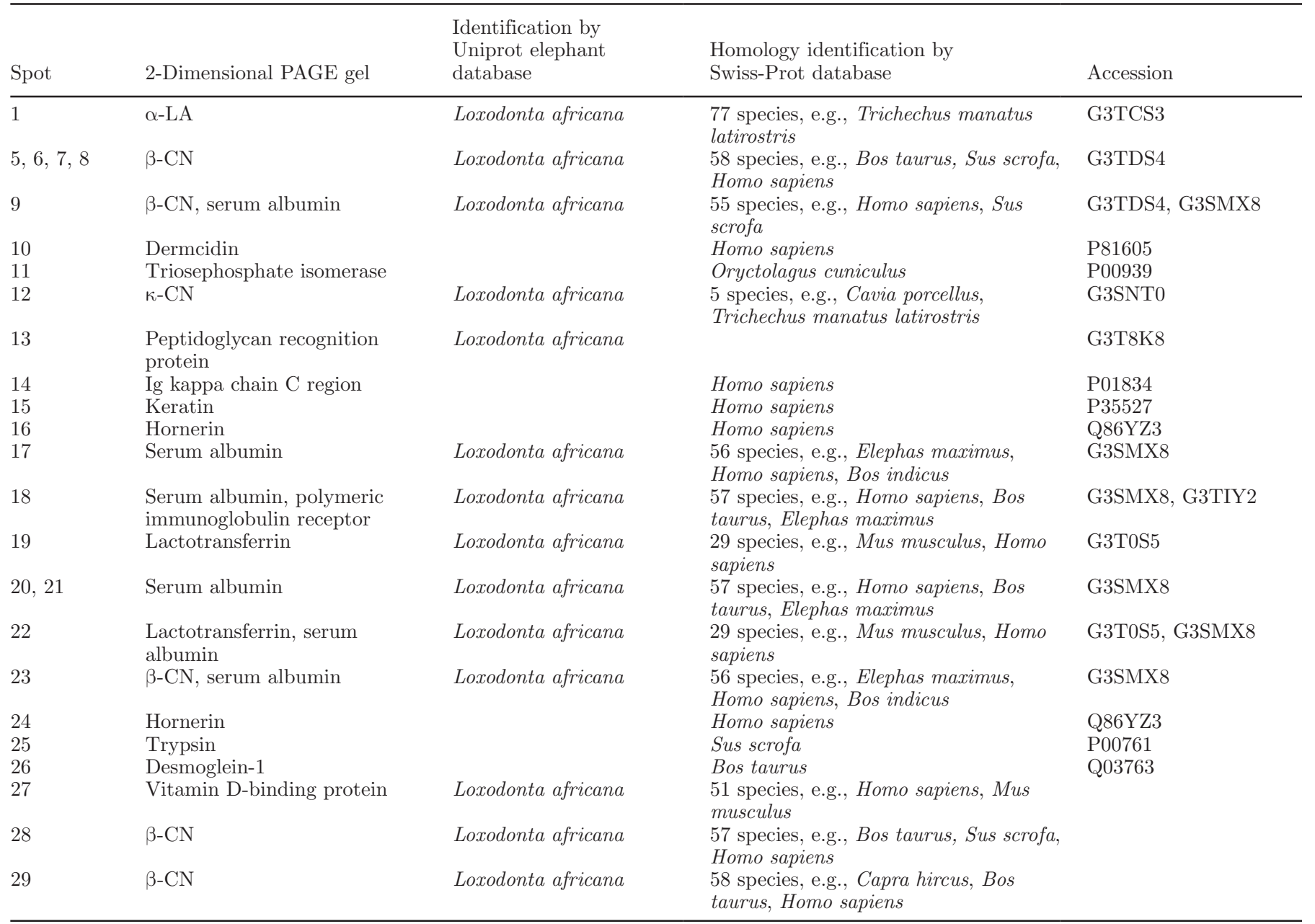

\section{pI 5-8}

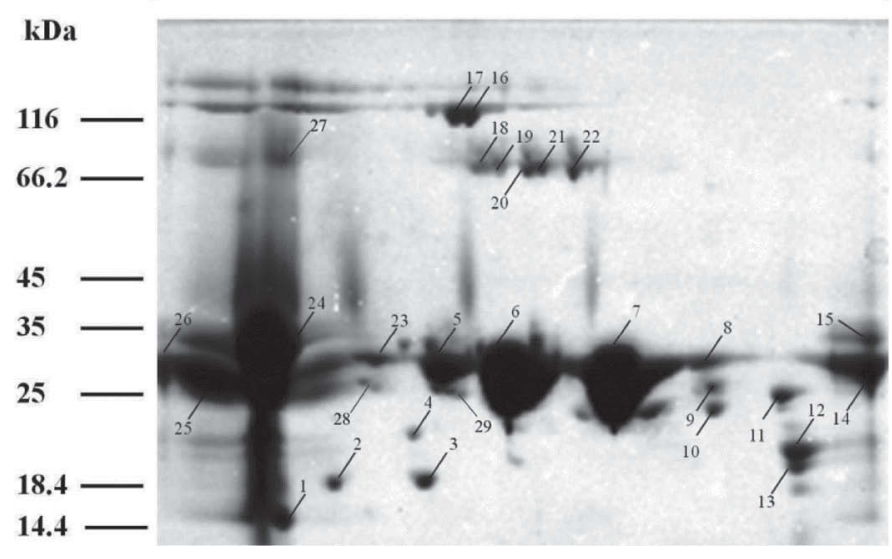

Figure 1. 2-Dimensional PAGE gel of African elephant milk proteins at mid $(12 \mathrm{mo})$ lactation. The protein spots, numbered and identified according to Table 1, were analyzed by Orbitrap MS (Thermo Scientific, Bremen, Germany). pI = isoelectric point. all identified as $\beta$-CN according to Orbitrap MS and were of approximately the same molecular weight. The different isoelectric-point values of the proteins might be due to different isomers with different posttranslational modifications, specifically phosphorylation of Ser residues.

Of interest is that only $\kappa-$ and $\beta-\mathrm{CN}$ were identified and not $\alpha-\mathrm{CN}$. The absence of $\alpha-\mathrm{CN}$ is not unusual, because human milk lacks $\alpha_{\mathrm{S}_{2}} \mathrm{CN}$. However, African elephant milk seems to lack both $\alpha_{\mathrm{S}^{-}}$and $\alpha_{\mathrm{S}_{2}} \mathrm{CN}$. This result supported the data available in the elephant genome database (Ensemble, elephant genome database, http://www.ensembl.org/index.html) where $\alpha-\mathrm{CN}$ genes are not present. This does not exclude the possibility that $\alpha_{\mathrm{S}^{-}}$and $\alpha_{\mathrm{S} 2^{-}} \mathrm{CN}$ are present in such low amounts that they are not detectible by current techniques and should be validated by mRNA sequencing in future research. The relative amounts of selected proteins were quantified on 2D PAGE of African el- 
ephant milk using PD QUEST (Bio-Rad), and the ratio of $\kappa-\mathrm{CN}$ to $\beta$-CN was found to be approximately 1:8.5. A similar ratio is observed in camel and rat milk compared with that of bovine milk (1:5; Eigel et al., 1984; Martin et al., 2003).

Before any conclusions were derived regarding the AA sequences of the African elephant from the NCBI database, the gene sequences were revisited. An error was detected in the $\mathrm{N}$-terminal region of the $\beta$-CN. It is likely that exon 1 of the $\beta-\mathrm{CN}$ is lacking in the database. The size of the intron sequence occurring between exon 1 and exon 2 is probably similar to that of the bovine $\beta-\mathrm{CN}$ gene, approximately 1,800 nucleotides. Exon sequences 1 to 9 were aligned and the AA sequence derived by opening at the initiation codon up to the stop codon in exon 8. The Expasy UniProtKB sequences (G3U197_LOXAF, G3TDS1_LOXAF, and G3TDS4_LOXAF) were derived from an Ensemble automatic analysis pipeline and should be considered as preliminary data.

Based on the genomic sequence available on the NCBI website (NW_003573450), the second protein sequence (G3TDS1_LOXAF) with a supplementary Glu residue between exons 6 and 7 is surprising. On the basis of the genomic sequence, if correct, exon 4 is excluded or skipped and thus the presence of peptide TVENLSSSEIRQFYSE in the first protein sequence (G3U197_LOXAF) is not possible. In addition, sequence G3TDS1_LOXAF deviates from the other 2 by the absence of the last $2 \mathrm{AA}$ residues (AV) of the protein (SV or IV in horse and human, respectively), whereas all species have a Val as C-terminal residue.

The intron following exon 4, which in the African elephant NCBI database is abnormally long, begins with a GCGAT sequence, which is not a canonic intron splice donor sequence. In all the species for which the sequences of $\beta-C N$ genes are known, exon 4 is $27 \mathrm{nu}-$ cleotides long and specifies a 9-AA sequence containing a multiple phosphorylation site such as TVENLSSSE (Grosclaude and Martin, 1997). Exon 4 in all species is followed by an intron sequence beginning with GTAAG. Such a structure exists in the African elephant $\beta-C N$ gene with a transversion of $\mathrm{G}$ to $\mathrm{A}$, leading to the loss of the splicing donor site, which becomes ATAAG. Such a situation was previously observed in the goat species with the $\mathrm{G}$ allele at the $\alpha_{\mathrm{S1}^{-}} \mathrm{CN}$ locus that also provoked the skipping of exon 4 . However, it is worth mentioning an exception. In the equine species, $\beta-\mathrm{CN}$ displays an exon 4, which comprises 45 nucleotides and results in the peptide sequence TVESLSSNEPDSSSE identified as such from the genome sequence (NCBI Reference Sequence: NC_009146.2), whereas the PDSSSE peptide was previously suspected to be encoded by an additional exon 4' (Miranda et al., 2004). This exon is however followed by a canonical intron splice donor site GTAAG.

The third sequence (G3TDS4_LOXAF) is not consistent with the genomic sequence elements available because exon 3, that specifies the peptide KEEIIVSTE, is absent from this sequence, suggesting its elimination during the maturation of primary transcripts, that is, exon skipping. This is highly unlikely if one refers to the genomic sequence (NCBI, NW_003573450). Indeed, a sequence AAGGAAGAAATTATTGTATCTACTGAG, encoding the peptide sequence KEEIIVSTE, bordered upstream by a polypyrimidic stretch ending with ACAG and a splice site donor GTAAG in $3^{\prime}$, is found approximately 100 nucleotides upstream of the unrecognized exon 4 . Therefore the most likely sequence of the African elephant $\beta-\mathrm{CN}$ is that given in Figure 2.

The AA sequences of African elephant $\beta-\mathrm{CN}$ and $\kappa-\mathrm{CN}$ are shown in Figures 2 and 3, respectively. The MS data gave information such as estimated isoelectric point, unique peptides identified, nonunique peptides identified, peptide score, molecular weight, as well as the protein length, which were all used to identify the proteins. The underlined peptide sequences were identified by Orbitrap MS from gel digests of individual protein spots on 2D PAGE gels and were unique to that of African elephant milk proteins. The remainder of the sequences were filled in by the program.

A multiple sequence alignment of $\beta-\mathrm{CN}$ sequences of African elephant, human, horse, mouse, pig, goat, sheep, water buffalo, and cow, with the 15-AA signal sequence included, is shown in Figure 3. The protein sequences were retrieved from http://www.ncbi.nih.gov.

The sequence alignment showed several properties common to all the $\beta$-CN. These included the absence of Cys residues, the presence of multiple $N$-terminal region phosphorylation sites (residues 15-19), Pro richness (39 Pro residues), as well as a negatively charged $N$-terminus with a high number of Glu residues. It was evident from the alignment that African elephant $\beta-\mathrm{CN}$ had an extended C-terminal, similar to the proteins of human, horse, mouse, and pig. It contained many charged AA so that it was more hydrophilic than the bovine $\beta-\mathrm{CN}$ sequence. The missing residues between 13 and 25 resulted in the absence of several charged or polar Glu and Ser residues found in most species. This property was also shared with human $\beta$-CN. Additionally, in the sequence between residues 15 to 26 (VTQVNKQKPEGV) of African elephant $\beta$-CN, unique AA replacements were noted. This led to a distribution of charged, or hydrophilic, and hydrophobic residues similar to the human protein but different compared with the other species.

Hydropathy plots of the $\beta-\mathrm{CN}$ sequences showed regions of the AA sequences that are hydrophilic and 


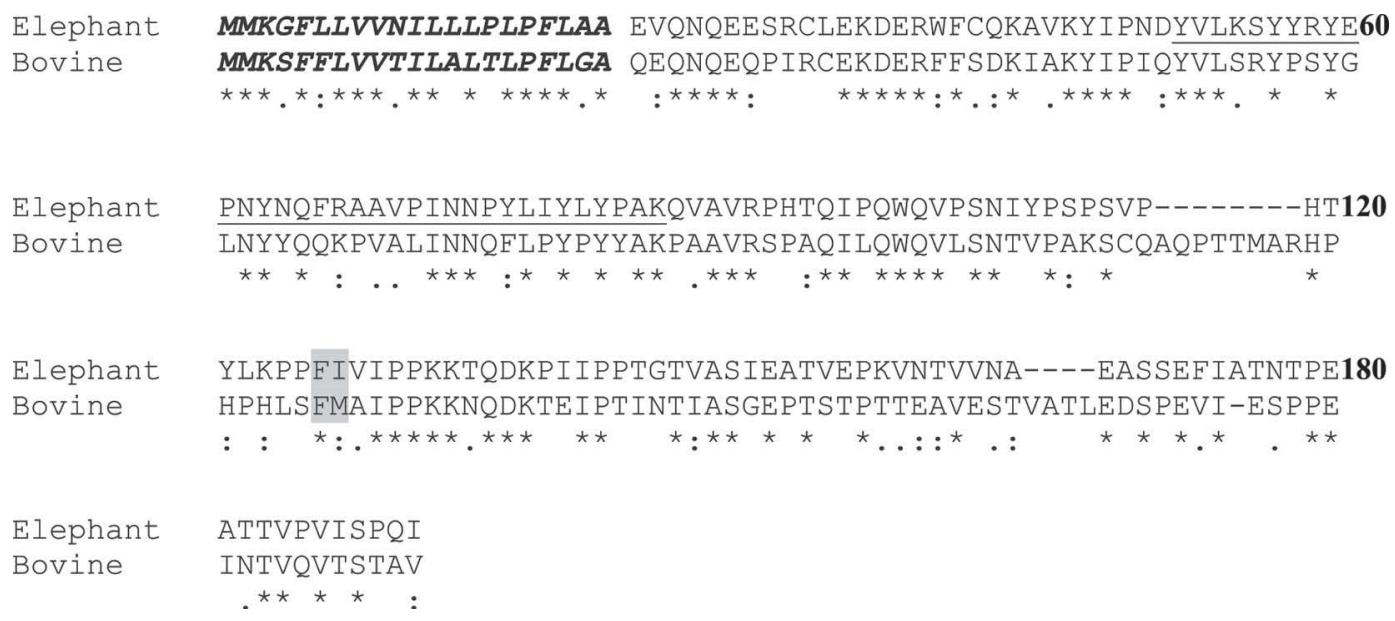

Figure 2. Sequence alignment of African elephant and bovine $k-C N$. The asterisks beneath the alignment indicate highly conserved AA residues between the 2 species. Colons and periods indicate conservative and semiconservative substitutions, respectively. The 21-AA signal sequence is included in the alignment and is shown in bold italics. Amino acid residues forming the chymosin-sensitive bond are indicated by a rectangular block. The underlined peptide sequences were identified by Orbitrap MS (Thermo Scientific, Bremen, Germany) and were unique to African elephant $\alpha-\mathrm{LA}$.

hydrophobic, and may therefore provide a possible indication of how they might interact with each other, or with other proteins or $\mathrm{CN}$, according to the model of Horne $(1998,2006)$. Figure 4 depicts the hydropathy plot of $\beta-C N$ from cow and African elephant. The plots of the ruminant proteins, sheep, goat and water buffalo, as well as of pig, were almost the same as that of the cow, whereas that of nonruminants, human, and mouse were more hydrophobic in region 155 to 172 . Because of the similarities, only the hydropathy plot of $\beta-\mathrm{CN}$ from cow is shown as representative. The African elephant $\beta$-CN hydropathy plot was very different from that of the ruminants. In total, the African elephant $\beta-\mathrm{CN}$ contained more hydrophilic stretches compared with bovine $\beta-\mathrm{CN}$, which may suggest that African elephant $\beta-\mathrm{CN}$ may interact differently inside the $\mathrm{CN}$ micelle, so that the hydrophilic parts may be exposed on the surface. In region 95 to 120 it is specifically a Met and Pro that are exchanged with a Lys and Ser, respectively. Although the $\beta$-CN of nonruminants such as human and pig also show less hydrophobicity in this region, this region is not as explicitly hydrophilic as in the African elephant protein.

To investigate the surface properties of African elephant $\kappa-\mathrm{CN}$, which are crucial in electrostatically stabilizing the CN micelle according to accepted models (Horne, 1998), hydropathy plots were used. The AA sequences as well as hydropathy plots of ruminant (cow, goat, and sheep) $\kappa$-CN were found to be very similar, and the bovine hydropathy plot was used as representative for all subsequent comparisons. Although most of the $\mathrm{CN}$ micelle models were drawn from experimental work with bovine $\kappa-\mathrm{CN}$, it is more likely that the other ruminants, goat and sheep $\kappa-\mathrm{CN}$, will behave in the same way during $\mathrm{CN}$ micelle formation. The alignment of bovine and African elephant $\kappa$-CN sequences (Figure 2) shows approximately $50 \%$ AA sequence identity, with most of the substitutions being conservative.

The comparison of the hydropathy plots of bovine and African elephant $\mathrm{k}$-CN (Figure 5) shows very few differences. A section of the plots between residues 65 and 85 has juxtaposed hydropathic features due to several charged residues that occur in the bovine protein, which have been substituted with hydrophobic ones in the elephant protein. This difference may have an effect on the interaction with other $\mathrm{CN}$ within the $\mathrm{CN}$ micelle. The C-terminal sections after the chymosinsensitive bond at position 126 to 127 are highly conserved and also displayed almost identical hydropathy profiles (Figure 6). These observations suggested that the African elephant $\kappa$ - $\mathrm{CN}$ would functionally behave in the same manner as the $\kappa-\mathrm{CN}$ of all other species, exposing the charged C-terminal on the surface of the $\mathrm{CN}$ micelle, thus avoiding flocculation.

The above results imply that the CN micelles in African elephant milk would consist mainly of $\beta$-CN. Milk of the African elephant was destabilized by $62 \%$ ethanol, which is comparable to that of ewe (Fava et al., 2014), goat (Guo et al., 1998), and buffalo (Unnikrishnan et al., 1988), and therefore deemed less stable than cow milk, which is destabilized by $75 \%$ ethanol. The milk of ewe and goat also has a much lower content of $\alpha_{\mathrm{S1}^{-}}$ and $\mathrm{\kappa}-\mathrm{CN}$, which is given as a reason why these milks are less stable to ethanol and heat (Horne and Muir, 1990; Horne 2008). If the proposed model of micelle formation (Horne, 2006) is applied, almost all African 


\begin{tabular}{|c|c|}
\hline Elephant & MKVFILACLVAFALG GREKEEIIVSTE--ESVTQ------VNKQKPEGVKHE-EQQREDE 45 \\
\hline Human & MKVLILACLVALALA ARETIESLSSSE--ESITE-----Y--KQKVEKVKHEDQQQGEDE \\
\hline Horse & MKILILACLVALALA AREKEELNVSSETVESLSSNEPDSSS-EEKLQKFKHEGQQQREVE \\
\hline ouse & MKVFILACLVALALA RETTFTV-SS--ETDSISSEESVEHINEQKLQKVNLMGQLQAEDV \\
\hline Pig & MKLLILACFVALALA RAKEELNASGETVESLSSSEES ITHISKEKIEKLKREEQQQTENE \\
\hline Goat & MKVLILACLVALALA REQEELNVVGETVESLSSSEESITHINK-KIEKFQSEEQQQTEDE \\
\hline Sheep & MKVLILACLVALALA REQEELNVVGETVESLSSSEESITHINK-KIEKFQSEEQQQTEDE \\
\hline W. Buffalo & MKVLILACLVALALA RELEELNVPGEIVESLSSSEESITHINK-KIEKFQSEEQQQMEDE \\
\hline \multirow[t]{2}{*}{ Cow } & MKVLILACLVALALA RELEELNVPGEIVESLSSSEESITRINK-KIEKFQSEEQQQTEDE \\
\hline & $\cdot \quad * \star * * *: \quad . \quad .: \quad: \quad .: \quad: * *:$ \\
\hline lephant & $\underline{\mathrm{HQNK}}$ IQPLFQPQPLVYPFAE--PIPYTVFPPNAI PLAQP IVV---LPFPQPEVKQLPEAK105 \\
\hline uman & HQDKIYPSFQPQPLIYPFVE--PIPYGFLPQNILPLAQPAVV---LPVPQPEIMEVPKAK \\
\hline lorse & RQDKISGFVQPQPVVYPYAE--PVPYAVVPQSILPLA-PPI----LPFLQPEIMEVSQAK \\
\hline louse & LQAKVHSSIQSQPQAFPYAQAQTISCNPVPQNIQPIAQPPVVPSLGPVISPELESFLKAK \\
\hline Pig & RQNKIHQFPQPQPLAHPYTE--PIPYPILPQNILPLAQVPVVV---PLLHPEVMKDSKAK \\
\hline oat & LQDKIHPFAQAQSLVYPFTG--PIPNS-LPQNILPLTQTPVVV--PPFLQPEIMGVPKVK \\
\hline Sheep & LQDKIHPFAQAQSLVYPFTG--PIPNS-LPQNILPLTQTPVVV--PPFLQPEIMGVPKVK \\
\hline W.Buffalo & LQDKIHPFAQTQSLVYPFPG--PIPKS-LPQNIPPLTQTPVVV--PPFLQPEIMGVSKVK \\
\hline \multirow[t]{2}{*}{ Cow } & LQDKIHPFAQTQSLVYPFPG--PIHNS-LPQNIPPLTQTPVVV--PPFLQPEVMGVSKVK \\
\hline & 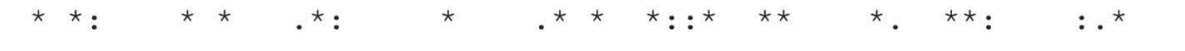 \\
\hline Lephant & ETIFPRQKLMSFLKSPV-MPFFDPQIPNLGTDLENLHLPLPLLQPLRHQLHQPLAQTPVL165 \\
\hline Human & $\overline{\text { DTVYTKGRVMPVLKSPT-IPFFDPQIPKL-TDLENLHLPLPLLQPLMQQVPQPIPQTLAL }}$ \\
\hline Horse & ETILPKRKVMPFLKSPI-VPFSERQILNP-TNGENLRLPVHLOQPFMHQVPQSLLQTLML \\
\hline Mouse & ATILPKHKQMPLLNSETVLRLINSQIPSL-ASLANLHLPQSLVQL-LAQVVQAFPQTHLV \\
\hline Pig & ETIVPKRKGMPFPKSPA-EPFVEGQSLTL-TDFEVLS--LPLLQSLMHQIPQPVPQTPMF \\
\hline Goat & ETMVPKHKEMPFPKYPV-EPFTESQSLTL-TDVEKLHLPLPLVQSWMHQP PQPLSPTVMF \\
\hline Sheep & ETMVPKHKEMPFPKYPV-EPFTESQSLTL-TDVEKLHLPLPLVQSWMHQPPQPLPPTVMF \\
\hline W.Buffalo & EAMAPKHKEMPFPKYPV-EPFTESQSLTL-TDVENLHLPLPLLQSWMHQPPQPLPPTVMF \\
\hline \multirow[t]{2}{*}{ Cow } & EAMAPKHKEMPFPKYPV-EPFTESQSLTL-TDVENLHLPLPLLQSWMHQPHQPLPPTVMF \\
\hline & 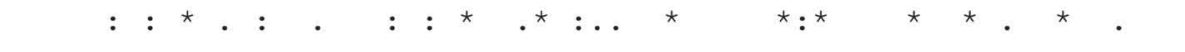 \\
\hline Elephant & $\underline{\text { P----LPLSLPKVLPVPQQVIPYPQRGRPIQNLQLYEEPLLDPTRKIYPVAQPLAPVYNP } 225}$ \\
\hline Human & PPQPLWSVPQPKVLPIPQQVVPYPQRAVPVQALLLNQELLLNPTHQIYPVTQPLAPVHNP \\
\hline Horse & PSQPVLSPPQSKVAPFPQPVVPYPQRDTPVQAFLLYQDPRLGPTGELDPATQPIVAVHNP \\
\hline Mouse & SSQTQLSLPQSKVLYFLQQVAPFLPQDMSVQDLLQYLELL-NPTVQFPATPQHSVSV--- \\
\hline Pig & APQPLLSLPQAKVLPVPQQVVPFPQRDMPFQALLLYQDPLLGPLQGFYPVPQPVAPVYNP \\
\hline Goat & PPQSVLSLSQPKVLPVPQKAV--PQRDMPIQAFLLYQEPVLGPVRGPFPILV-------- \\
\hline Sheep & PPQSVLSLSQPKVLPVPQKAV--PQRDMPIQAFLLYQEPVLGPVRGPFPILV-------- \\
\hline W. Buffalo & PPQSVLSLSQSKVLPVPQKAVPYPQRDMPIQAFLLYQEPVLGPVRGPFPIIV-------- \\
\hline \multirow[t]{2}{*}{ Cow } & PPQSVLSLSQSKVLPVPQKAVPYPQRDMPIQAFLLYQEPVLGPVRGPFPIIV-------- \\
\hline & $: \quad \star \star \star \cdot{ }^{\star}: . \quad: \quad *^{\star}:$ \\
\hline Elepha & $\underline{\text { VAV }}$ \\
\hline Human & $\overline{\mathrm{ISV}}$ \\
\hline Horse & VIV \\
\hline Mouse & --- \\
\hline Pig & $\mathrm{V}--$ \\
\hline Goat & --- \\
\hline Sheep & --- \\
\hline W.Buffalo & --- \\
\hline & --- \\
\hline
\end{tabular}

Figure 3. Multiple sequence alignment of $\beta-\mathrm{CN}$ from 9 mammalian species. The 15-AA signal sequence is included in the alignment and is shown in bold italics. The AA numbering excludes the signal sequence. The asterisks beneath the alignment indicate highly conserved AA residues between species. Colons and periods indicate conservative and semiconservative substitutions, respectively. The underlined peptide sequences were identified by Orbitrap MS (Thermo Scientific, Bremen, Germany) and were unique to African elephant $\alpha$-LA. W. Buffalo $=$ water buffalo.

elephant $\kappa-\mathrm{CN}$ molecules, with their low amounts relative to the $\beta-\mathrm{CN}$, should be distributed over the micelle surface to present their negatively charged C-terminals to repel other $\mathrm{CN}$ micelles and avoid flocculation, that is, if the $\kappa-\mathrm{CN}$ is the sole protein in the micelle to fulfill this role. Because regions 95 to 120 and 210 to 220 of 
the African elephant $\beta-\mathrm{CN}$ were hydrophilic, compared with those of other mammals, it might be that these regions would hamper the hydrophobic association of the $\beta$-CN inside the micelle and would instead be presented on the micelle surface. In this case, these regions may possibly replace the role of the hydrophilic center regions of $\alpha-\mathrm{CN}$ to aid the $\kappa-\mathrm{CN}$ in keeping the micelles in suspension.

The multiple alignment of $\alpha$-LA from African elephant with that of 15 other species (Brahman, water buffalo, yak, sheep, pig, Weddell seal, harbor seal, ringed seal, human, guinea pig, shrew, mouse, possum, and wallaby) is shown in Figure 6. From the alignment, several AA were seen to be unique to the African elephant $\alpha$-LA sequence. At position 19, 26, 27, 59, 65, and 98, the elephant sequence had Ala, Phe, Thr, Lys, His, and Ser, respectively. Residue His65 was the

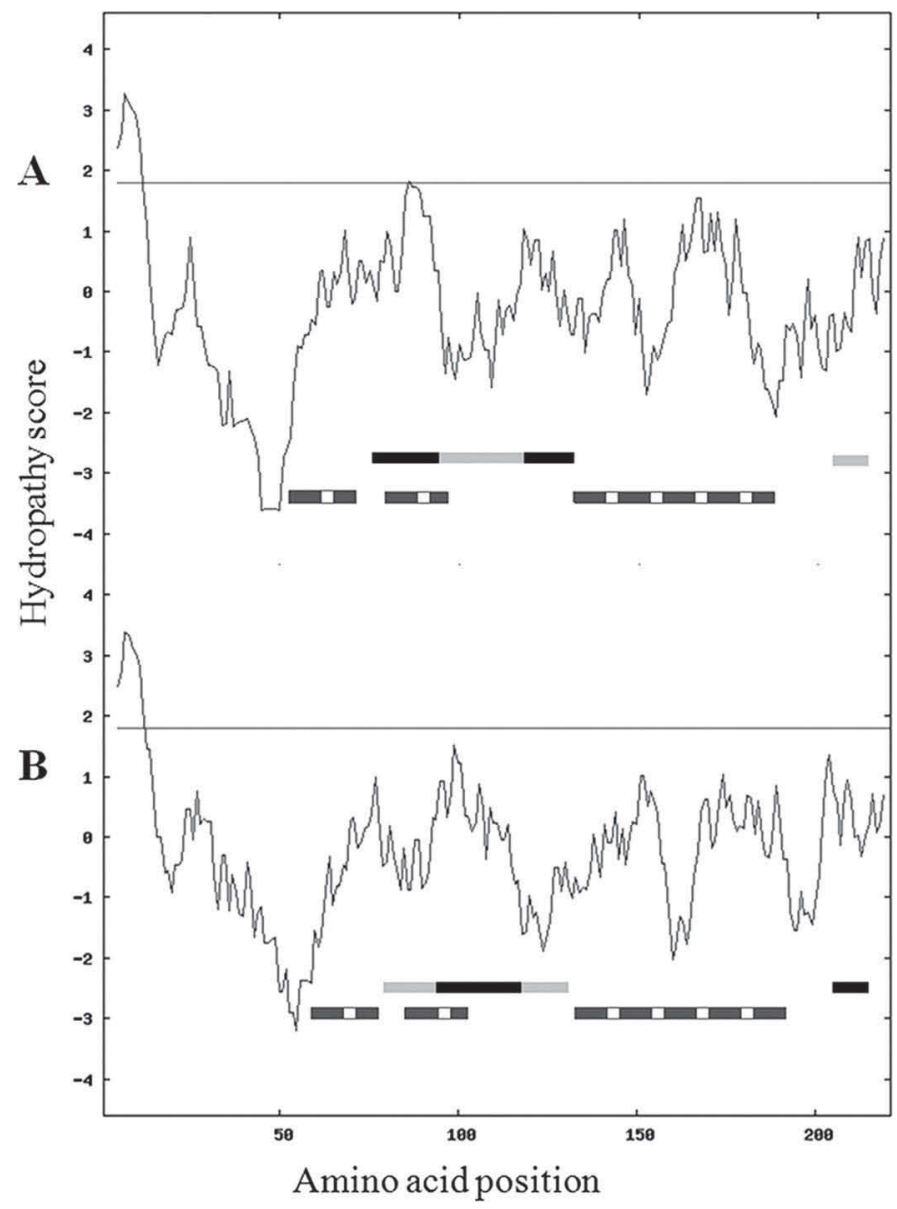

Figure 4. Kyte and Doolittle hydropathy plots for African elephant (A) and bovine (B) $\beta$-CN. The bars show differences in the distribution of hydrophobic (black) and hydrophilic (gray) regions. In African elephant $\beta$-CN, regions between AA 95 to 120 and 210 to 220 are hydrophilic, and 80 to 95 and 120 to 135 are hydrophobic, whereas in the bovine $\beta-\mathrm{CN}$, the opposite is observed. Checkered regions indicate the regions of high homology in AA sequences.

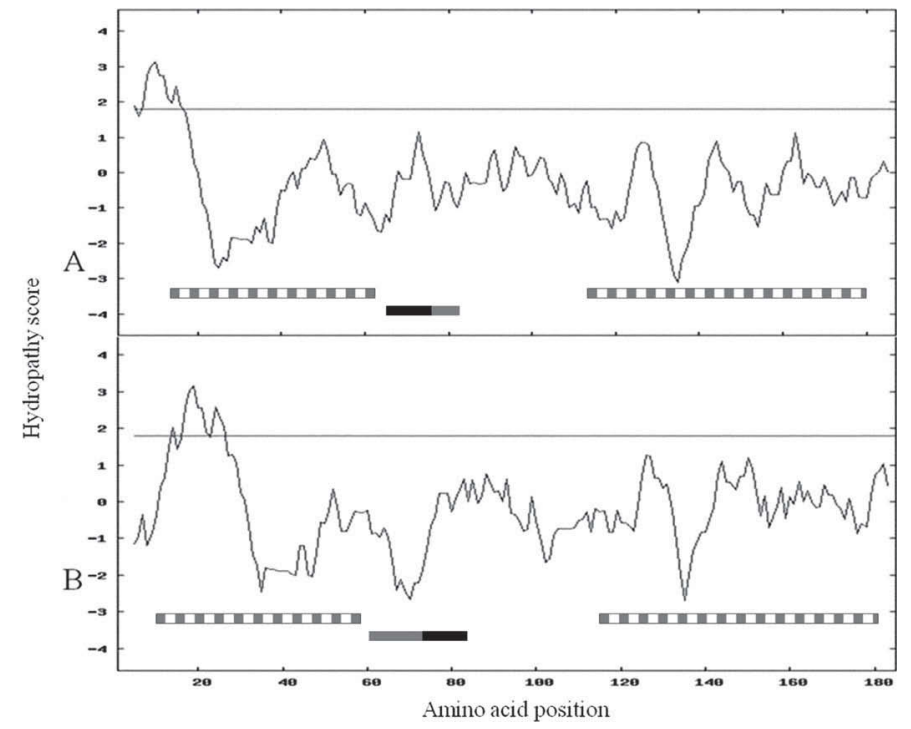

Figure 5. Kyte and Doolittle hydropathy plots for African elephant (A) and cow (B) $\kappa$-CN. The bars show differences in the distribution of hydrophobic (black) and hydrophilic (gray) regions. In cow $\kappa-\mathrm{CN}$, a region between AA 65 and 75 is hydrophilic, and a region between AA 75 and 85 is hydrophobic, whereas in the African elephant $\kappa$ - $\mathrm{CN}$, the opposite is observed on the corresponding regions. Checkered regions indicate high homology in AA sequences and those that display the same hydropathy.

only AA residue that is not polar or charged, compared with the same position of other species. The other sequences contained charged or hydrophilic residues at position 65. Residue Ser98 is similarly uncharged and polar, whereas in other species the AA at that position are either polar and charged or hydrophobic. Additionally, Phe31 and His32, which are important residues for glucose binding (Ramakrishnan and Qasba, 2001), are conserved among all the $\alpha$-LA sequences in the alignment. Figure 7 shows the similarity relationship between the $\alpha$-LA sequences in the alignment. The ruminant $\alpha$-LA sequences possess high AA sequence homology, and hence, a close relationship on the phylogenetic tree is observed. The African elephant $\alpha$-LA sequence showed the closest relationship to the protein of seals and human.

The homology model of $\alpha$-LA was modeled and superimposed on goat, pig, human, and bovine x-ray structures for comparison (Figure 8). The structure alignments showed that no major differences existed between these 5 structures, except for the region Leu105 to Leu110, where the $\alpha$-LA of African elephant, pig, and bovine assumed a helix conformation as opposed to the loose loop conformation of the human and goat protein.

Nevertheless, to further investigate the possible reason behind the presence of both lactose and oligosaccharides at high levels in African elephant milk, the 


\begin{tabular}{|c|c|}
\hline Elephant & MMSFVPLLLVGIL-FPAIQA KQFTKCELSQVLKDIDGYAGITLPEFTCTIFHISGYDTQT40 \\
\hline Guinea-pig & MMSFFPLLLVGIL-FPAVQA KQLTKCALSHELNDLAGYRDITLPEWLCI IFHISGYDTQA \\
\hline Pig & MMSFVSLLVVGIL-FPAIQA KQFTKCELSQVLKDMDGYGDITLPEWICT IFHISGYDTKT \\
\hline Sheep & MMSFVSLLLVGIL-FHATQA EQLTKCEAFQKLKDLKDYGGVSLPEWVCTAFHTSGYDTQA \\
\hline Mouse & MMHFVPLFLVCILSLPAFQA TELTKCKVSHAIKDIDGYQGISLLEWACVIFHTSGYDTQA \\
\hline Human & MRFFVPLFLVGIL-FPAILA KQFTKCELSQLLKDIDGYGGIALPELICTMFHTSGYDTQA \\
\hline Wallaby & MMSLLSLLLLGIA-LPATQA IDYRKCQASQILKEHGMDKVIPLPELVCTMFHISGLSTQA \\
\hline Possum & MMSLLPLLLIGIV-LPATQA KDYGKCELNQILRERGVDKVISLPELICTMFHSSGFSTET \\
\hline Yak & MMSFVSLLLVGIL-EHATQA EQLTKCEVFRELKDLKGYGGVSLPEWVCTTFHTSGYDTQA \\
\hline R.seal & MMSFVSLLLVGIM-FPAIQA KQFRKCELSQVLKDMDGFRGIALPKWICTAFHTSGYDTQT \\
\hline W.Buffalo & MMSFVSLLLVGSL-FHATQA EQLTKCEVFRELRDLKDYGGVSLPEWVCTAFHTSGYDTQAA \\
\hline H. seal & MMCFVSLLLVGIM-FPAIQA KQFTKCELSLVLKDVYGFRGIALPEWICTAFHTSGYDTQT \\
\hline W. seal & MMSFVSLLLIGIM-FPAIQA KQFTKCELSQVLKDMDGFGGIALPEWICTAFHTSGYDTQT \\
\hline Cattle & MMSFVSLLLVGIL-FHATQA EQLTKCEVFRELKDLKGYGGVSLPEWVCTAFHTSGYDTQA \\
\hline Shrew & -MLFVPLLLVGTL-FPAIQA TWLTKCELHKRLKDIFGYKDITAAEWICTIFHTSGFDTQA \\
\hline \multirow[t]{2}{*}{ Brahman } & MMSFVSLLLVGIL-FHATQA EQLTKCEVFRELKDLKDYGGVSLPEWVCTIEHTSGYDTQA \\
\hline & $:{ }^{*}::: \quad: *{ }^{*} \quad * * \quad: .: \quad * \quad: \quad * * * *{ }^{*}::$ \\
\hline Elephant & IVNNNGSTEYGLFQISNKYWCRDHQIPQSRNICDISCDKFLDDDLTDDMMCAKKILDS-K100 \\
\hline Guinea-pig & IVKNSDHKEYGLFQINDKDFCDSSTTVQSRNICDISCDKLLDDDLTDDIMCVKKILDI-K \\
\hline Pig & IVHDNGSTEYGLFQINNKLWCRDNQI-QSKNICGISCDKFLDDDLTDDMMCAKKILDN-E \\
\hline Sheep & IVQNNDSTEYGLFQINNKIWCKDDQNPHSRNICNISCDKF LDDDLTDDIVCAKKILDK-V \\
\hline Mouse & VVNDNGSTEYGLFQISDRFWCKSSEFPESENICGISCDKLLDDELDDDIACAKKILAI-K \\
\hline Human & IVENNESTEYGLFQISNKLWCKSSQVPQSRNICDISCDKFLDDDITDDIMCAKKILDI-K \\
\hline Wallaby & EVNNHSNKEYGIFQISNNGWCAEKQEDVANSVCGILCSKF LDDDITDDIECAKKILQLPE \\
\hline Possum & EVDNNNHKEYGIFQISSNGWCAEKQEDVERSVCGILCSKLLDDDITDDIVCAKKILQLPE \\
\hline Yak & IVQNNDSTEYGLFQINNKIWCKDDQNPHSSNICNISCDKFLDDDLTDDIMCVKKILDK-V \\
\hline R.seal & IVSNNGSTEYGLFQINNKFWCRDNQILQSRNICDISCDKFLDDDLTDDMICAKKILDK-E \\
\hline W. Buffalo & IVQNNDSTEYGLFQINNKIWCKDDQNPHSSNICNISCDKFLDDDLTDDIMCVKKILDK-V \\
\hline H. seal & IVSNNGSTEYGLFQINNKFWCRDNQILQSRNICDISCDKFLDDDLTDDMICAKKILDK-E \\
\hline W. seal & IVSNNGSTEYGLFQINNKCWCRDNQILQSRNICDISCDKFLDDDLTDDMICVKKILDK-E \\
\hline Cattle & IVQNNDSTEYGLFQINNKIWCKDDQNPHSSNICNISCDKFLDDDLTDDIMCVKKILDK-V \\
\hline Shrew & KVSNNGSTEYGLFQISNKHWCKSEQIPQSKNICNIPCEKLLNDDLTDDIACAKKILDR-K \\
\hline \multirow[t]{2}{*}{ Brahman } & IVQNNDSTEYGLFQINNKIWCKDDQNPHSSNICNISCDKF LDDDLTDDIMCVKKILDK-V \\
\hline & 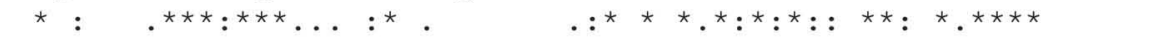 \\
\hline Elephant & GIDYWIAHK=LKSEKLEWLCEKL124 \\
\hline Guinea-pig & GIDYWIAHKALESDKLEQWYCEAQ \\
\hline Pig & GIDYWI AHKA LESEKLDQWLCEKM \\
\hline Sheep & GINYWI AHKA LESEKLDQWLCEKL \\
\hline Mouse & GIDYWHAYKAMCSEKLEQWRCEKP \\
\hline Human & GIDYWIAHKALCTEKLEQWLCEKL \\
\hline Wallaby & GLGYWKAHETFCLEDLDQWRC--- \\
\hline Possum & RLDHWKAHNT F CRENLDQWNC--- \\
\hline Yak & GINYWIAHKALESEKLDQWLCEKL \\
\hline R.seal & GIDYWIAHKALLSEKLEQWHCEKL \\
\hline W.Buffalo & GINYWLAHKA LESEKLDQWLCEKL \\
\hline H.seal & GIDYWIAHKHLESEKLEQWHCEKL \\
\hline W. seal & GIDYWIAHKHLESEKLEQWHCEKL \\
\hline Cattle & GINYWIAHKA LESEKLDQWLCEKL \\
\hline Shrew & GMGYWIAYEALESEQLEQWLCKDL \\
\hline Brahman & 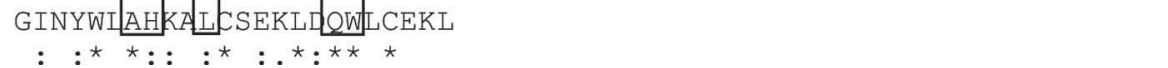 \\
\hline
\end{tabular}

Figure 6. Multiple sequence alignment of $\alpha$-LA from 16 mammalian species. The asterisks, colons, and periods beneath the alignment indicate highly conserved AA residues $(>12 / 16)$ between species. The signal sequence is split from the rest of the sequence and is presented in italics. The rectangular blocks indicate residues that are important in normal functioning of the lactose synthase complex. The shaded areas represent AA unique to the African elephant protein. The underlined peptide sequences were identified by Orbitrap MS (Thermo Scientific, Bremen, Germany) and were unique to African elephant $\alpha$-LA. R. seal = ringed seal; W. Buffalo $=$ water buffalo; $\mathrm{H}$. seal $=$ harbor seal; W. seal $=$ Weddell seal.

structure of the lactose synthesis complex of African elephant $\alpha$-LA and $\beta-1,4-G T 1$ was also modeled (Figure 9). In bovine lactose synthase, AA residues of
a-LA (Ala106, His107, Leu110, Gln117, and Trp118) are involved in binding to $\beta-1,4-\mathrm{GT} 1$, whereas residues (Phe31 and His32) are responsible for interaction with 


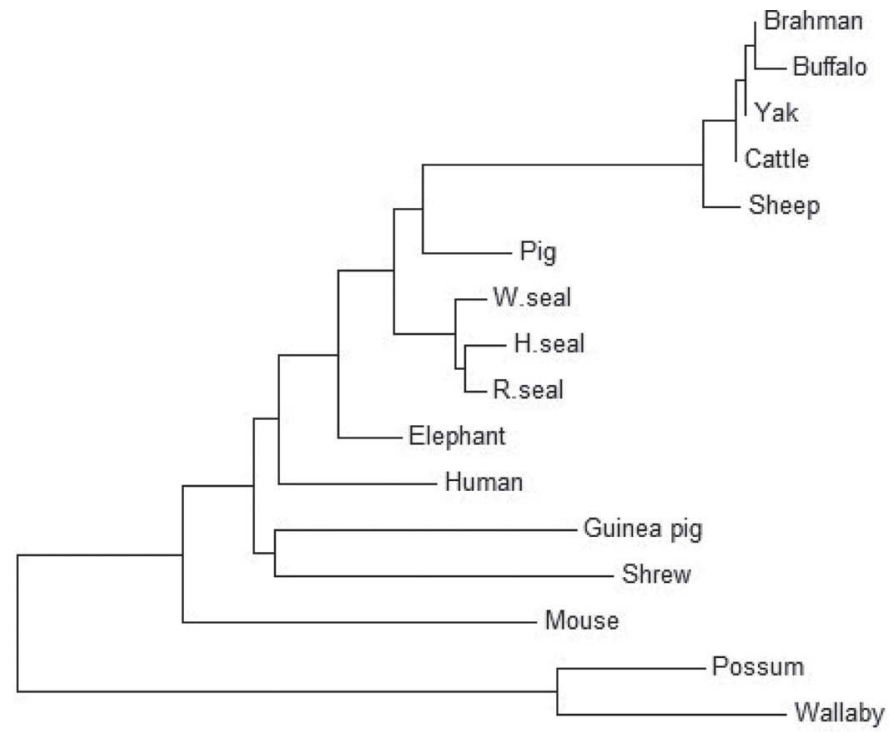

0.1

Figure 7. A phylogenetic tree showing the relationship among $\alpha$-LA AA sequences of 16 different species. W. seal $=$ Weddell seal; $\mathrm{H}$. seal $=$ harbor seal; $\mathrm{R}$. seal $=$ ringed seal.

glucose (Ramakrishnan and Qasba, 2001). As is evident from the sequence alignment (Figure 6), these residues were conserved and their orientation and spatial arrangement (Figure 9) were similar to those of the bovine lactose synthase crystal structure (Ramakrishnan and Qasba, 2001). It therefore appeared unlikely that the structure of the African elephant $\alpha-\mathrm{LA}$, as well as the lactose synthase complex, was different from those of other mammals and should not impair the kinetics of lactose synthesis, and in turn favor oligosaccharide

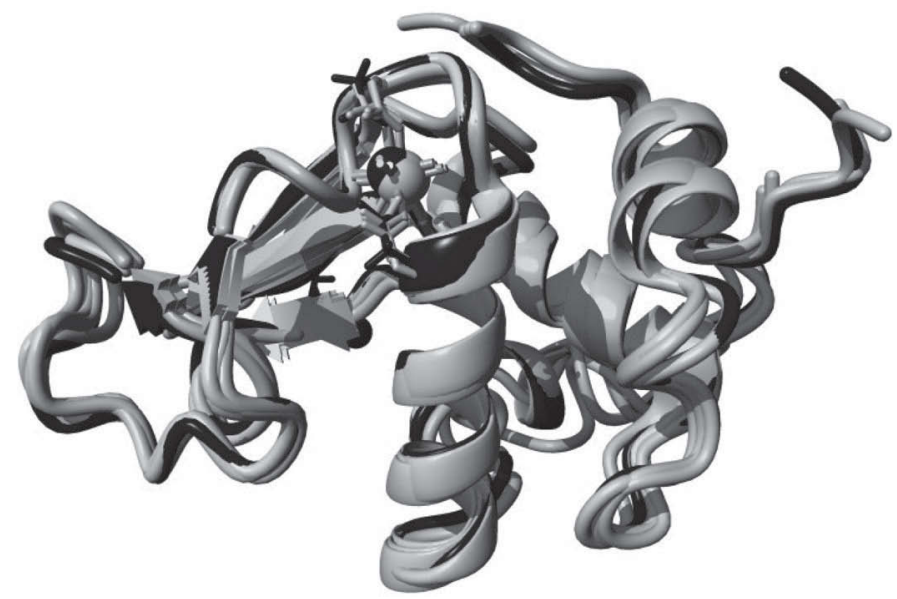

Figure 8. Homology model of African elephant $\alpha$-LA (black) superimposed on human, bovine, pig, and goat (all in gray) $\alpha$-LA crystal structures in ribbon representation. synthesis in African elephant milk. The reason for the unique saccharide composition should therefore be searched elsewhere in the saccharide synthesis pathway, such as the other galactosyltransferases. Derived from the different branch types of the oligosaccharides found in African elephant milk, it is suspected that 8 different galactosyltransferases might be involved (Urashima et al., 2009). Isoglobotriose [ $\mathrm{Gal}(\alpha \mathrm{l}-3) \mathrm{Gal}(\beta 1-4) \mathrm{Glc}]$ is the most abundant of the oligosaccharides in Asian and African elephant milk (Uemura et al., 2006; Osthoff et al., 2008). The $\beta$-galactosyltransferase, that links galactose via an $\alpha$ l-3 bond to the galactosyl moiety of the lactose, would therefore be the most obvious enzyme on which a kinetic study should be conducted to investigate its competition with $\alpha$-LA for lactose, which consequently would result in a disproportionate synthesis of oligosaccharides or lactose.

\section{CONCLUSIONS}

The milk proteins of the African elephant are less stable to ethanol precipitation than cow milk. We also observed that they displayed unique AA sequences, which might affect their structure-function role to different degrees. Whereas the $\kappa$-CN might fulfill the same role in the $\mathrm{CN}$ micelle structure as in other mammals, the role of the $\beta-\mathrm{CN}$ could be different. It contained 2 additional hydrophilic regions between residues 95 to 120 and 210 to 220 , which might affect hydrophobic association of the $\mathrm{CN}$, so that these regions could protrude on the $\mathrm{CN}$ micelle surface and contribute to keeping it in suspension. Because the African elephant $\mathrm{CN}$ micelle seems to consist only of $\kappa-\mathrm{CN}$ and $\beta-\mathrm{CN}$, at the high ratio of approximately 1:8.5, such a dual role of $\beta-\mathrm{CN}$ might be necessary. Although the $\alpha-\mathrm{LA}$ of African elephant contained several unique AA replacements, compared with other species, the tertiary

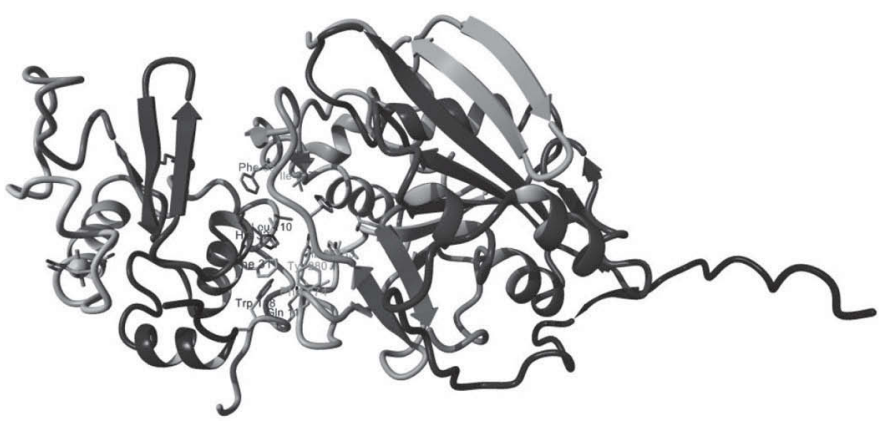

Figure 9. A close-up representation of the African elephant lactose synthase complex model showing residues that are involved in the interaction between $\alpha$-LA (left) and $\beta$-1,4-galactosyltransferase 1 (right). 
structure of this protein, as well as the lactose synthase complex, seemed to be similar.

\section{ACKNOWLEDGMENTS}

This research was supported by the University of the Free State (Bloemfontein, Republic of South Africa) and National Research Foundation (Pretoria, South Africa).

\section{REFERENCES}

Boisnard, M., D. Hue, C. Bouniol, J. C. Mercier, and P. Gaye. 1991 Multiple mRNA species code for two non-allelic forms of ovine alpha s2-casein. Eur. J. Biochem. 201:633-641.

Bradford, M. M. 1976. A rapid and sensitive method for the quantitation of microgram quantities of protein utilizing the principle of protein-dye binding. Anal. Biochem. 72:248-254.

De Kruif, C. G. 1999. Casein micelle interactions. Int. Dairy J. 9:183188

Eigel, W. N., J. E. Butler, C. A. Ernstrom, H. M. Farrell, V. R. Harwalkar, R. Jenness, and R. M. Whitney. 1984. Nomenclature of proteins of cow's milk: Fifth revision. J. Dairy Sci. 67:1599-1631.

Farrell, H. M., Jr., R. Jimenez-Flores, G. T. Bleck, E. M. Brown, J. E. Butler, L. K. Creamer, C. L. Hicks, C. M. Hollar, K. F. Ng-KwaiHang, and H. E. Swaisgood. 2004. Nomenclature of the proteins of cows' milk: Sixth revision. J. Dairy Sci. 87:1641-1674.

Fava, L. W., I. C. Külkamp-Guerreiro, and A. T. Pinto. 2014. Evaluation of physico-chemical characteristics of fresh, refrigerated and frozen Lacaune ewes' milk. Arq. Bras. Med. Vet. Zootec. 66:19241930.

Grosclaude, F., and P. Martin. 1997. Casein polymorphisms in the goat. Pages 241-253 in IDF Seminar "Milk Protein Polymorphism II." Int. Dairy Fed., Palmerston North, New Zealand.

Guo, M. R., S. Wang, Z. Li, J. Qu, L. Jin, and P. S. Kindstedt. 1998. Ethanol stability of goat's milk. Int. Dairy J. 8:57-60.

Holt, C., J. A. Carver, H. Ecroyd, and D. C. Thorn. 2013. Invited review: Caseins and the casein micelle: Their biological functions, structures, and behavior in foods. J. Dairy Sci. 96:6127-6146.

Horne, D. S. 1998. Casein interactions: Casting light on the black boxes, the structure in dairy products. Int. Dairy J. 8:171-177.

Horne, D. S. 2006. Casein micelle structure: Models and muddles. Curr. Opin. Colloid Interface Sci. 11:148-153.

Horne, D. S. 2008. Casein micelle structure and stability. Pages 133 162 in Milk Proteins: From Expression to Food. A. Thompson, M. Boland, and H. Singh, ed. Academic Press, San Diego, CA.

Horne, D. S., and D. D. Muir. 1990. Alcohol and heat stability of milk protein. J. Dairy Sci. 73:3613-3626.

Igarashi, Y. 1995. An improved procedure for the preliminary fractionation of milk proteins. Int. Dairy J. 5:305-310.

Klee, W. A., and C. B. Klee. 1970. The role of $\alpha$-lactalbumin in lactose synthetase. Biochem. Biophys. Res. Commun. 39:833-841.

Krieger, E., G. Koraimann, and G. Vriend. 2002. Increasing the precision of comparative models with YASARA NOVA - A self-parameterizing force field. Proteins 47:393-402.

Kyte, J., and R. F. Doolittle. 1982. A simple method for displaying the hydropathic character of a protein. J. Mol. Biol. 157:105-132.

Martin, P., P. Ferranti, C. Leroux, and F. Addeo. 2003. Non-bovine caseins: Quantitative variability and molecular diversity. Pages 277-317 in Advanced Dairy Chemistry. Vol. 1: Proteins. P. F. F. Fox and P. L. H. McSweeney, ed. Kluwer Acad./Plenum Publ., New York, NY.

Marx, I. J., N. van Wyk, S. Smit, D. Jacobson, M. Viljoen-Bloom, and H. Volschenk. 2013. Comparative secretome analysis of Trichoderma asperellum $\mathrm{S} 4 \mathrm{~F} 8$ and Trichoderma reesei Rut C30 during solid-state fermentation on sugarcane bagasse. Biotechnol. Biofuels 6: 172 .

McCullagh, K. G., and E. M. Widdowson. 1970. The milk of the African elephant. Br. J. Nutr. 24:109-117.

Miranda, G., M.-F. Mahe, C. Leroux, and P. Martin. 2004. Proteomic tools to characterize the protein fraction of Equidae milk. Proteomics 4:2496-2509.

O'Farrell, P. H. 1975. High resolution two-dimensional electrophoresis of proteins. J. Biol. Chem. 250:4007-4021.

Osthoff, G., H. O. de Waal, A. Hugo, M. de Wit, and P. Botes. 2005. Milk composition of a free-ranging African elephant (Loxodonta africana) cow during early lactation. Comp. Biochem. Physiol. A Mol. Integr. Physiol. 141:223-229.

Osthoff, G., M. de Wit, A. Hugo, and B. I. Kamara. 2007. Milk composition of three free-ranging African elephant (Loxodonta africana africana) cows during mid lactation. Comp. Biochem. Physiol. B Biochem. Mol. Biol. 148:1-5.

Osthoff, G., L. Dickens, T. Urashima, S. L. Bonnet, Y. Uemura, and J. H. van der Westhuizen. 2008. Structural characterization of oligosaccharides in the milk of an African elephant (Loxodonta africana africana). Comp. Biochem. Physiol. B Biochem. Mol. Biol. 150:74-84.

Perkins, D. N., D. J. C. Pappin, D. M. Creasy, and J. S. Cottrell. 1999. Probability-based protein identification by searching sequence databases using mass spectrometry data. Electrophoresis 20:3551-3567.

Piersma, S. R., M. O. Warmoes, M. de Wit, I. de Reus, J. C. Knol, and R. J. Connie. 2013. Whole gel processing procedure for GeLC-MS/ MS based proteomics. Proteome Sci. 11:17.

Pike, A. C. W., K. Brew, and K. R. Acharya. 1996. Crystal structures of guinea-pig, goat and bovine alpha lactalbumin highlight the enhanced conformational flexibility of regions that are significant for its action in lactose synthase. Structure 4:691-703.

Ramakrishnan, B., and P. K. Qasba. 2001. Crystal structure of lactose synthase reveals a large conformational change in its catalytic component, the $\beta$-1,4-galactosyltransferase-1. J. Mol. Biol. 310:205-218.

Sharp, J. A., C. Lefèvre, and K. R. Nicholas. 2008. Lack of functional alpha-lactalbumin prevents involution in Cape fur seals and identifies the protein as an apoptotic milk factor in mammary gland involution. BMC Biol. 6:48.

Sievers, F., A. Wilm, D. Dineen, T. J. Gibson, K. Karplus, W. Li, R. Lopez, H. McWilliam, M. Remmert, J. Söding, J. D. Thompson, and D. G. Higgins. 2011. Fast, scalable generation of high-quality protein multiple sequence alignments using clustal omega. Mol Syst. Biol. 7:539

Stacey, A., A. Schnieke, M. Kerr, A. Scott, C. McKee, I. Cottingham, B. Binas, C. Wilde, and A. Colman. 1995. Lactation is disrupted by alpha-lactalbumin deficiency and can be restored by human alpha-lactalbumin gene replacement in mice. Proc. Natl. Acad. Sci. USA 92:2835-2839.

Swaisgood, H. E. 1993. Review and update of casein chemistry. J. Dairy Sci. 76:3054-3061

Uemura, Y., S. Asakuma, L. Yon, T. Saito, K. Fukuda, I. Arai, and T. Urashima. 2006. Structural determination of the oligosaccharides in the milk of an Asian elephant (Elephas maximus). Comp. Biochem. Physiol. A Mol. Integr. Physiol. 145:468-478.

Unnikrishnan, V., M. K. Bhavdasan, and M. K. Ramamurthy. 1988. Alcohol stability of buffalo milk. Indian J. Dairy Sci. 7:337-340.

Urashima, T., S. Asakuma, M. Kitaoka, and M. Messer. 2009. Milk oligosaccharides. Pages 295-349 in Advanced Dairy Chemistry. P. McSweeney and P. F. Fox, ed. Kluwer Acad./Plenum Publ., New York, NY

Urashima, T., T. Nakamura, A. Ikeda, S. Asakuma, I. Arai, T. Saito, and O. T. Oftedal. 2005. Characterization of oligosaccharides in milk of a mink, Mustela vison. Comp. Biochem. Physiol. A Mol. Integr. Physiol. 142:461-471.

Walstra, P. 1999. Casein sub-micelles: Do they exist? Int. Dairy J. 9:189-192 